\title{
Evaluating Learners' Communication Strategies within a Synchronous Cyber Environment
}

\author{
Ying-Chuan Wang \\ Macau University of Science and Technology, Macau SAR, China
}

\begin{abstract}
In order to increase the competitiveness of Taiwan in the international environment, the Taiwanese government has become aware of the importance of English in reforming English education and establishing a new language testing system in leading to more successful language learning. However, many scholars in Taiwan are dubious as to whether this reformed English education has really improved the English communicative ability of learners. The purpose of this study is, therefore, to investigate learners' communicative competence in terms of communication strategies, by means of administrating a set of communicative task based activities within a computer mediated environment to provide evidence of the current learning outcomes. Drawing upon the framework proposed by Bachman (1990), communication strategies could be identified. After the data collection, the learners' speech data were analysed based on the taxonomy of Poulisse (1993), and the findings revealed that the learners employed the re-conceptualisation strategy more frequently than the substitution strategy. A new strategy, named "additional strategy", was discovered during this study. Therefore, this study suggests that the importance of adopting a communicative task-based activity into classroom increases opportunities for learners to interact with each other to improve their communicative competence.
\end{abstract}

Index Terms-communicative competence, communication strategy, computer mediated environment, communicative task-based activity

\section{INTRODUCTION}

The government and people of Taiwan strongly perceive the importance of employing English in communication in order to achieve the government's intention of becoming the hub of Asia Pacific Operations in an increasingly globalised world. In addition to this, the Taiwanese government has announced that English may become the second official language in the next 8 to 10 years (Liao, 2004, p.121). Therefore, a great deal of attention has been placed on language learners and educators, as well as on the reform of English education with a view of improving the teaching and learning of the English language in Taiwan.

Today, more and more language teachers in Taiwan are willing to attempt to implement a "Communicative Language Teaching" (CLT) method, instead of traditional language teaching approaches such as Focus on Form Instruction (FFI) in their classrooms. With respect to CLT, this is an approach to the teaching of second or foreign language students that places great emphasis on helping students use the target language in a variety of contexts. That is, CLT makes use of real-life situations that necessitate communication in order to develop learners' communicative competence. Therefore, the learners will have an adequate ability to apply knowledge of both formal and sociolinguistic aspects of a language to communicate. FFI is not regarded as an effective teaching approach for developing communicative skills of language learners, and is no longer a recognised method for the CLT curriculum developed in 2001. According to the findings of the research carried out by Chang (2001) in junior high schools and Chang and Huang (2001) in senior high schools, teachers in secondary schools believe in CLT approaches for improving language teaching and learning practice. Hence, the CLT approach has, unsurprisingly, prevailed in most English learning and teaching contexts in Taiwan. However, after employing CLT in language education for many years, some researchers such as Liao (2006) still question if there is any significant improvement on learners' communicative competence in English language. As a result of this, this researcher was motivated to conduct this study.

\section{A. The Purpose of the Study}

The present study is an investigation of the learners' communicative competence in terms of communication strategies. It aims to examine the communication strategies of Taiwanese senior high school language learners who have passed the intermediate level of The General English Proficiency Test (GEPT), while lacking in language resources. Therefore, the object of this study is to understand the learners' communicative competence in terms of communication strategies, in order to provide some information to improve such competence in the language learning and teaching contexts. Furthermore, by means of evaluation of the learners' communicative competence, this will lend potential to remain language learners in terms of successfully learning the English language. As well as this, it will allow the language teachers to be aware of the current strengths and weaknesses of the learners in order to modify their teaching approach by promoting the notion of communicative competence. 


\section{B. Research Questions}

1. How do Taiwanese EFL learners cope with deficiencies in their communicative competence in the English language?

2. What differences exist between the high scoring and low scoring learners when employing compensatory strategies?

\section{LITERATURE REVIEW}

\section{A. The Notion of Communicative Competence}

Hymes (1972) was the first person to propose the notion of communicative competence, thus providing a great stimulus to the current major focus in grammatical competence (Schachter, 1990). Hymes's (1972) theory is, originally, a development of Chomsky's (1965, p. 4) distinction. Chomsky's (1980, p. 59) distinction refers to grammatical competence and pragmatic performance. In contrast to Chomsky's distinction, Hymes's notion of communication competence concerns both knowledge and ability (Widdowson, 1989, p.130). Hymes (1972) believes that the model of competence must take communication into account and, therefore, divides "communicative competence" into two categories; the knowledge of language, and the capacities in language-use underlying performance in real time, that is, "knowledge" and "ability for use" (Hymes, 1967, 1972). It is said that communicative competence is a dynamic, interpersonal construct and relies on "the cooperation of all the participants involved" (Savignon, 1983, p. 9) so only by means of performance in the process of communication, the communicative competence of individuals can be examined.

Canale and Swain (1980) and Canale (1983) later carried out the work of defining and developing the theory of communicative competence proposed by Hymes (1972). Their framework of communicative competence consists of four components: grammatical competence, sociolinguistic competence, strategic competence, and discourse competence. Subsequently, the frameworks of Canale and Swain (1980) and Canale (1983) of communicative competence have been modified over the years (Brown, 2000).

Bachman (1990) was the first researcher to explicitly divide language knowledge into organizational and pragmatic competence. The most prominent modification should be recognised as Bachman's (1990) distinction, which concerns "communicative language ability". The expanding framework of Bachman (1990) is more comprehensive and explicit than previous models proposed by Canale and Swain (1980) and Canale (1983). Through refining the earlier models, Bachman (1990) suggests "the ability to use language communicatively involves both knowledge of competence in the language, and the capacity for implementing, or using this competence" (p. 81). Consequently, in Bachman's (1990) framework, he explicitly classified the composition of "knowledge" and the composition of a "skill", which remains ambiguous in the model of Canale (Fulcher \& Davidson, 2007, p. 42). Another improvement in the framework of Bachman (1990) is that his framework not only presented extensions of earlier models but also intended to "characterize the processes by which the various components interact with each other and with the context in which language use occurs" (p. 81). Consequently, the framework of communicative language ability proposed by Bachman (1990, p. 84) includes three components: language competence, strategic competence, and psychophysiological mechanisms.

This researcher remains aware that Bachman and Palmer (1996) later revised Bachman's (1990) framework and renamed their model to include language use and language test performance. However, their model is not relevant to this study. As a result, the framework of Bachman and Palmer (1996) will not be discussed further.

In addition, many researchers such as McNamara (1996), Young (2000) and Chalhoub-Deville (2003), Chalhoub-Deville and Deville (2005) argue that Bachman's (1990) model presents a cognitive/psycholinguistic ability model, rather than interactional competence model. Even though Bachman (2002) in his publication shows his position has been advanced in 1990, he still distinguishes communicative language ability between the "ability targeted" and "the context in which they are observed" (Chalhoub-Deville, 2003, p. 372) in his model.

As Jacoby and Ochs (1995) suggest, the abilities, actions, and activities do not belong to the individual but are jointly constructed by all participants. Similarly, Swain (2001) believes that a dynamic representation of interaction is co-constructed by all participants in a given situations. Ultimately, Bachman's (1990) position is considered to be different from those who consider the "language use situation primarily as a social event in which ability, language users, and context are inextricable meshed" (Chalhoub-Deville, 2003, p. 372). That is, the social perspective of interaction. Therefore, interactional competence researchers propose their position as "ability-in language user-in context".

Even though interactional competence researchers provide their view of a dynamic interaction in which the abilities, actions, and activities do not belong to the individual but are co-constructed by all participants, this research focuses on the investigation of an individual's performance in various contexts rather than exploring the interactions between participants. As a result, the framework of Bachman (1990) provides a useful base for this research in order to identify strategic competence of Taiwanese learners of English.

\section{B. Communication Strategy}

There are three components included in strategic competence within Bachman's (1990) framework: assessment, planning, and execution. That is, assessing what is said, planning utterances, and executing the plan. In turn, the ability 
to assess the situation, plan an utterance verbally, and also perform an utterance is to successfully execute plans and achieve goals. More explicitly, in order for the plan to match the goal, language users have to analyse the given situation and their resources in respect of the goal in order to construct and select an appropriate plan. Communication strategies, as Ellis (1994) agrees, are a part of the planning process and are useful for the speakers to tackle the problems that prevent them from executing their initial plan.

Færch and Kasper (1983) more explicitly indicate that communication strategies are used in the situations based on the problems that take place within the planning or execution phase. When problems occur within the planning phase, it shows that the language learners confront a problem in constructing or developing a plan which could provide adequate means in order to assist them in achieving their communication goals (Færch \& Kasper, 1983, p. 23).

Ellis (1994, p. 398) argues that the taxonomy of Færch and Kasper (1983) provides a basis for classifying the communication strategies into categories. Moreover, the taxonomy of Færch and Kasper (1983) has been regarded as a psycholinguistic framework, allowing for the classification of the communication strategies into categories (Smith, 2003).

However, Bialystok (1990) and Poulisse (1990, 1993) criticise the Færch and Kasper (1983) taxonomy as it involves several problems that result in the difficulty of identifying the communication strategies. For example, Bialystok (1990) considers all plans developed by the speakers are conscious; this opposes Færch and Kasper's (1983) claim that consciousness about the problem does not exist in all situations. Poulisse $(1990,1993)$ also criticises the fact that some definitions of strategies are not clear, for instance, a difficulty in distinguishing "topic avoidance" and "meaning replacement". In some instances, the definitions of these categories do not indicate weather they should be based on either the view of the learner or the observer. Poulisse (1990) argues that creating new types of category for slightly different forms of utterances resulted in too many categories being included in their taxonomy. Therefore, it is suggested that there is a need to redefine the communication strategies and to make the taxonomy more general.

Poulisse (1993, p. 163), in particular, criticises and indicates that the taxonomy of Færch and Kasper (1983) lacks insight into the cognitive processes underlying communication strategy use. Similarly, some researchers such as Kellerman et al. (1987) at Nijmegen University criticised the existing typologies of communication strategies as product-oriented. Such typologies focused on linguistic products because they showed a tendency to illustrate strategy types with isolated examples. As a result, these typologies were merely descriptive. Most importantly, the product-oriented classifications of communication strategies failed to distinguish the psychological process from the linguistic product. The criteria that were adopted to distinguish between the various subtypes of compensatory strategy were not explicitly related to the processes underlying communication strategy used in the earlier studies, generalizations made with respect to these processes were missed out. The Nijmegen University group therefore took such problems into account and proposed an alternative taxonomy to classify the compensatory strategies in a process-oriented manner.

\section{The Nijmegen Project}

The Nijmegen project was intended solely to study the compensatory strategies where the focus was to investigate the proficiency effect; the relationship between communication strategy (CS) use in L1 and L2 and the effectiveness of various CS types (Poulisse, 1990, 1993). Compensatory strategies were employed when the speakers encountered lexical problems. Lexical problems emerged when speakers had established a preverbal message containing chunks of conceptual, grammatical and linguistic information. Subsequently, the speakers discovered that they could not access the correct lexical items in order to match all of the intended expressions.

The Nijmegen Project classifies the compensatory strategy into two main strategies depending on whether the learners use the conceptual knowledge resource or the linguistic knowledge resource. However, Poulisse (1993) highlighted a weakness in the Nijmegen Project. For example, the strategies of 'transfer' and 'morphology creativity' could not be classified as completely different subtypes of the linguistic strategies from the process-oriented perspective. This results in such strategies sometimes being difficult to identify because some L2 words exist as L1 words. It is also possible to combine the holistic and analytic strategies in an utterance so it becomes difficult to be clear-cut in classifying the utterance in either the holistic or analytic strategies. Additionally, the problem of identifying the conceptual strategies and linguistic strategies of transfer has also been noticed. As Poulisse (1990, 1993) claims, there is no purer explanation of the conceptual strategies and linguistic strategies as the interaction of those that may occur and when there are similar underlying substitution processes.

As such weaknesses exist in the Nijmegen Project, Poulisse (1993) attempted to establish her taxonomy as much improved against other traditional taxonomies. Through refining her taxonomy, Poulisse believes that it has been more comprehensive in classifying and coding the use of compensatory strategies. The following section will be devoted to the discussion of the taxonomy of Poulisse (1993).

\section{The Taxonomy of Poulisse}

In Poulisse's taxonomy, she terms the three types of communication strategies as: substitution, substitution plus, and re-conceptualization strategies instead of linguistic and conceptual strategies. Poulisse's (1993) taxonomy was important for this researcher to consider as the basis to identify the speech production of the participants in her study. Due to Poulisse's taxonomy having been developed to classify the compensatory strategy from a process-oriented 
perspective, it is useful to employ this typology into this current study to explore learners' underlying cognitive processes in their choice of strategy.

1. Substitution strategy

The purpose of using this strategy is to replace the intended lexical item with another in order to overcome the linguistic limitation. There are two ways to do this; one is to use related items such as "animal" for "rabbit" and the other way is the corresponding L1 item such as Dutch "voorwoord" for "preface" (Poulisse, 1993, p. 180). In the taxonomy of Poulisse (1993), it was intended that these two strategies were classified as one as it was discovered that they shared a certain level of similarity when considering lexical access of L1 and L2. Poulisse (1993) claims that the speakers decide to either change or omit from one or more features of a particular chunk, which are both kinds of substitution strategies.

2. Substitution Plus Strategy

The second type of compensatory strategy in Poulisse's (1993) taxonomy is the substitution plus strategy. She explains the reason behind the name of such strategies being "Substitution Plus" is because they are always employed in combination with substitution strategies. This strategy considers "the out-of the ordinary application of L1 or L2 morphological and/or phonological encoding procedures" (Poulisse, 1993, p. 180), which may affect both L1 and L2 lexical items.

3. Re-conceptualisation Strategy

This strategy provides manipulation for the speakers to explain the item by encoding the conceptual features. For instance, the speaker may opt to encode the conceptual features by listing its possessions, or by substituting the word for a related concept that shares certain critical properties. By using this strategy, the speaker can also decide to add further background information in order for the listener to take advantage of understanding the context whilst interpreting the message.

Poulisse (1993, p. 182) concludes that basically, only the substitution strategy and re-conceptualisation strategy can be used on their own, as the substitution plus strategy is always used in combination with substitution strategies. These three major types of compensatory strategy comprise a taxonomy which differs from the traditional psycholinguistic approach taxonomies such as the taxonomy of Færch and Kasper (1983).

The intention of this researcher is to investigate the lack of lexical items used by the learners. So the taxonomy of Poulisse (1993) was chosen to examine the learners' strategies. As the language systems of Chinese and English are very different, this researcher does not expect the strategies of foreignizing and morphological creativity (i.e. the substitution plus strategy) to be included and will be seen in the speech production of this data. As a result, only two types of compensatory strategy suggested by the taxonomy of Poulisse (1993), that is, substitution strategy and re-conceptualisation strategy will be of concern in this study.

More recently, Littlemore (2003) elaborates on the taxonomy of Poulisse (1993) by classifying the main three different types of compensatory strategy into more specific subtypes. In doing so, it has been helpful for this researcher to analyze her data more effectively. Littlemore (2003, p. 337) identified six strategies to be included in the substitution strategy. They are original analogical/metaphoric comparison, conventional analogical/metaphoric comparison, literal comparison, and super-ordinate. With reference to re-conceptualisation strategies suggested by Poulisse (1993), Littlemore (2003, p. 338) proposes five subtypes. She considers that the analysis of the target items by describing the components of this item, and its activity, place function and the emotion inspired by it.

In addition, Littlemore (2003) seemed not to include the strategy of adding further information in her elaboration, which was mentioned in taxonomy of Poulisse (1993). As this researcher considered its importance and decided to include this strategy into this study in order to identify learners' speech data. As a result, the learners' cognitive process on encoding the target items could be more comprehensively explored.

The Littlemore's (2003) typology could facilitate this study to achieve the above goal and to allow this researcher to investigate how the learners operate and use the communication strategies based on their cognitive process from their linguistic products. It also allows the analysis of the similarities and differences of the strategy usage between higher and lower scoring learners.

\section{RESEARCH MeTHOD}

This study was designed to administer a computer mediated oral activity to investigate the communicative competence in terms of communication strategies of the Taiwanese EFL learners in a senior high school through communicative tasks. In order to examine and investigate the research aims and questions of this study, the mixed research strategies were chosen, that is, both quantitative and qualitative research methodologies were adopted in the collection of data from the study, and considered throughout the response to the purpose of the study.

\section{A. Sampling}

In this study, the researcher aimed to target a particular group who had passed a language test, that is, the GEPT. The reason behind studying participants who had passed the intermediate level of the GEPT is that the intermediate level of the GEPT is equivalent to the level of B1 Threshold (LTTC, 2005). The interpretation of the level of B1 Threshold is that the test participants can clearly understand the main points of familiar matters and deal with most situations whilst 
travelling. They can also produce simple text connections on familiar topics and describe their experiences, and briefly give reasons and explanations for opinions and plans (Council of Europe, 1996).

Another consideration pertains to computer knowledge; the participants involved in this study need to interact individually with the computer when taking this activity. Therefore, some knowledge of computers was necessary. The Taiwanese Ministry of Education has implemented computer lessons in elementary school since 1995, so it was not necessary for to train the participants or to require them to have the ability to use computers when partaking in this study.

As quantitative and qualitative methods are employed in this study, the sample size needs to be manageable. Therefore, the researcher requires a moderate sample size in order to provide a representative amount of speech data. Finally, the decision was made to include 35 participants from a prestigious private secondary school situated in southern Taiwan.

\section{B. Instrumentation}

There are few computer mediated oral activities that include investigations of communicative competence available in the commercial market in Taiwan. In order to carry out this study, the researcher decided to design an oral activity that investigates learners' communication strategies within a computer based environment.

A total of 12 task items were presented in this activity and were divided into two types of task; type A and type B. Both types involved six task items and each participant was required to select four out of six task items to complete this section. The decision made by the learners was dependent on the learners' interests and confidence on the task items, so some task items were selected more frequently than the others.

The images chosen by Subject A were not shown on the screen of Subject B. The screen of Subject B only presented some instructions. Therefore, Subject B was not able to predict which item Subject A had chosen and was about to describe. Subject B was allowed to request more information about the image chosen by Subject A in order to gain full comprehension of the description of the image on screen given by Subject A to identify the item.

After Subject A described four out of the six images individually, Subject B was required to name these items in Mandarin in order to show if he or she had understood Subject A's description. When Subject B announced the correct name of the four objects in the activity in Mandarin, this activity was completed. It was the performance of Subject A that was of concern to the two native speaking assessors and two coders at this stage, as Subject B only played a supporting role. The computer recorded the oral performance of each subject within a pair of participants and all speech data collected were later scored by two native English-speaking assessors based on the learners' English proficiency and the level of comprehension. The participants' responses were also coded, which was carried out by the researcher and her colleague according to the taxonomy of Poulisse (1993).

\section{Procedure}

In June 2011 a pilot study was administrated to eight participants who volunteered to take part in this study. The aim of administering a pilot study was to ensure that the task items had been selected appropriately for the participants, and that the layout of the design of the computer mediated activity was clear and easy enough for participants to use.

A small scale item trial was carried out in the form of piloting a set of communicative task based activities within a computer mediated environment. The eight participants were grouped into pairs to undertake this activity. After finishing this activity, an informal interview took place. The eight participants involved in the pilot study were invited into the language lab and encouraged to express their feelings concerning the carrying out of this activity in order to gain the participants' opinions regarding the layout and task items involved.

Consequently, there were some improvements to be made after the pilot study and interviews. For example, replacing inappropriate images that had not been selected by any participants, adding conditions to the instructions for their indecisive behaviour in selection, which resulted in them abandoning their items of choice. After this improvement, in the main study the task items were decided on and included these images; in type A, jellyfish, cactus, binoculars, otter, dragonfly and roundabout, and in type B, ostrich, ointment, grasshopper, mirage, squid, and scarecrow.

In the pilot study stage, a training session took place to practice grading and coding the responses collected from the pilot study. The learners' speech data was transcribed by the researcher and her colleague and subsequently both sets of transcribed data were compared to search for differences. Later, the differences were discussed and an agreement was reached, so a training session could be held.

It was important to employ two native speaking assessors to ensure that all scores and responses coded were as reliably as possible. The speech data collected from the activity in the pilot study was scored by the two assessors based on the rating components of the GEPT speaking test, provided on the official website of GEPT (2006). The components included pronunciation and intonation, vocabulary and grammar, intelligibility, relevance and fluency. The learners' English proficiency in this study was scored based on a given five-point scale ranking system form ranging from very un-satisfied "(1)", to completely satisfied "(5)" to indicate the different levels in terms of these five components.

The main study was carried out at the aforementioned school and the computer based oral activity was administrated in December 2011. This activity lasted around fifteen minutes and the participants' responses were recorded as "wav" files in their computer's hard drive. 


\section{Discussion OF FINDINGS}

\section{A. Types of Communication Strategies Employed by the Learners}

According to the taxonomy of Poulisse (1993), compensatory strategies are identified as being one of three types: substitution, substitution plus, and re-conceptualisation strategies. Due to the differences between Chinese and English language systems, the substitution plus strategy might not appear in the learners' response. It was decided that only the substitution and re-conceptualisation strategies would be adopted in this study to classify the speech sample.

Between these two compensatory strategies, the re-conceptualisation strategy was used more than twice as frequently as the substitution strategy. This implied that the learners' methods of identifying the objects tended to employ more re-conceptualisation, such as listing the intended lexical items one by one, selecting two lexical items from one lexicon, which could be combined into one new word, or adding further information (Poulisse, 1993, p. 118).

This finding could, therefore, be interpreted in terms of the participants favouring the use of the re-conceptualisation strategy based on their chosen methods, which were more inclined to encode the conceptual features through the analysis and manipulation of the intended concept.

This finding also supports the argument of Littlemore (2003). The learners tended to use the re-conceptualisation strategy because it involved being more direct and more related to the immediate perceptual world without involving "different level of abstraction" (Littlemore, 2003, p. 339), when compared to the substitution strategy, the re-conceptualisation strategy was less direct and more idiosyncratic. It is tempting to infer that the learner's belief in using re-conceptualisation strategy could contribute to a higher level of comprehension of their interlocutors, where direct interpretation of the immediate perceptual word is easier to process.

The strategy of describing or comparing the individual parts of the target item was employed the most frequently compared to the other strategies within the subtypes of the re-conceptualisation strategy. According to Poulisse (1993), the learners tried to be comprehensible, so the use of the re-conceptualisation strategy allowed the listeners to increase their comprehension of the utterances, but the use of this strategy requires more effort during their communication. Littlemore (2003) also claims that the reason behind componential comparison being regarded as the most successful re-conceptualisation strategy is that it helps to minimise cross-cultural differences between two interlocutors by offering direct information.

Comparatively, two strategies, that is metaphoric comparison and strategy of expressing emotion, were used much less frequently. The metaphoric comparison in the substitution strategy was used much less frequently $(1.2 \%)$. The findings suggest that the learners seemed to not be accustomed to using a metaphorical means to describe the target items, so this strategy was adopted far less frequently than the others. Littlemore and Low (2006) argue that "being metaphoric is more an aspect of personal style and as such, some speakers might actively reject it" (p. 280). It is reasonable to speculate that the learners in this study did not make a habit of imprinting their own personal styles upon their utterances or became afraid that their metaphors would not easily be understood. Similarly, as Littlemore (2003) suggests the learners believed that the metaphoric comparison involved a personal concept concerning the target items, where sometimes a certain level of agreement is required, which is not easily transferred from person to person. Perhaps for this reason, the learners were afraid of using it as it may occasionally be treated by their listeners as an error or ambiguous expression. Therefore, the speakers had to make sure their listeners could understand their metaphoric comparison before using it.

Excluding the metaphoric comparison strategy, the strategy of expressing emotion to the target items, in particular, was employed at a very low percentage rate; only 4.8\%. This finding supports the viewpoint of Littlemore (2003, p.339) who argues that the emotion category is a rather subjective category and concerns personal points of view. Based on the Oriental culture, people tend to be more conservative and implicit in relation to their feelings in contrast to Western culture. Part of this reason could be that the emotions inspired by the target items could be down to individual feeling, and this feeling reflected on the speakers and listeners need to reach agreement. Therefore, based on the percentage rate of strategy usage, it could be assumed that this strategy was considered as a less used and ineffective strategy requiring more mental effort than other subtypes.

An additional strategy was found in the learners' speech data and was later identified by the researcher in this study. This additional strategy was different from that identified in Tarone's (1977) study, who proposed "literal translation" in the strategy of Conscious Transfer, this occurs "when the learner translates word for word from the native language" (p. 198). For example, a Mandarin speaker translates the equivalent Mandarin expression to English as: "He invites him to drink" to describe two people toasting one another. This example was provided in the strategy of literal translation. However, the additional strategy was different from this because it was employed to translate the name of the target items from Chinese to English.

The importance of this study is pertinent in the light of the fact that it presents this additional strategy, which had not been proposed by either Poulisse (1993) or Littlemore (2003). It is probably the case that most research concerning communication strategies was carried out in western countries, such as Denmark or France, where the language systems are comparable to that of English. This offers the chance for the learners to transfer their L1 to English. For example, "a cuffer" (hairdresser, French: coiffeur) in Poulisse's (1990, p. 62) study.

Even though the findings show that only six participants employed the additional strategy into their responses and the percentage rate of the additional usage was only $2.2 \%$, it was important to remain aware of every strategy adopted by 
the learners in order to overcome their English vocabulary deficiency. This additional strategy was only employed by the learners who basically attempted to request that their listeners indicated the target item by means of directly translating it from their L1 (Chinese) to L2 (English). For example, Student A described "Jellyfish" by directly translating Chinese names of the target items to English and said "two words in Chinese...water...water... the first word and the second word is mother".

The reason for the learners' use of this additional strategy may be that both participants and their interlocutors speak the same language, that is, Chinese. This resulted in the participants attempting to translate the Chinese name of target objects into English words to their interlocutors and requesting them to assemble each word to guess the target items. However, when learners adopted this strategy too frequently, Chinese interlocutors may have been able to comprehend where English native assessors could not. In other words, even though the Chinese words have been directly translated into English, it is difficult for native speakers to make the intended meaning comprehensible. As a result, the learners who employed this additional strategy obtained a low level of comprehension to native speakers.

\section{B. The Differences in Usage of the Compensatory Strategy between the Higher and Lower Scoring Learners}

The findings illustrate that both the higher and lower scoring learners employed the use of the re-conceptualisation strategy twice as much more than substitution strategy. The findings also showed that both the higher and lower scoring learners used similar strategies in responding to the task items. The only difference was that the lower scoring learners used an additional strategy; namely the speakers requested the interlocutors to translate English words into Chinese and to assemble them to gain the Chinese name of the target objects.

It could be assumed that because the learners employed the additional strategy, they did not have sufficient English ability to express themselves well and so lost the confidence to express their intended meaning. Instead, they required their interlocutors to translate English words into Chinese to guess the name of the target object. For example, one of the lower score students attempted to describe the target item by using the strategy of place and activity first. However, later he found difficulties in his language resources. Subsequently, he developed a plan to request his interlocutor translate the English words into Chinese and then to assemble those words in order to gain the name of the target item.

Alternatively, the higher scoring learners had higher English proficiency, so they could understand how to convey the intended meaning effectively to facilitate their interlocutors through the choice of appropriate strategies. In other words, the higher scoring learners obtained much richer English resources enabling them to make their communication smooth and effective to convey their intended meaning through the choice of the appropriate strategy. Therefore, this could be the reason why the higher scoring learners did not use the additional strategy in their responses.

In relation to the substitution strategy, more lower scoring learners inclined to use the strategy of referring to the target item to a higher position within a hierarchy of the classification so that the learners only needed to utter the name of family to which the target items belongs, for example, 'it is an insect' or 'a kind of plant'. This did not require the learners to use a higher level of vocabulary to describe the target objects.

Interestingly, more higher scoring learners used the literal comparison strategy and the provision of extra information strategy than other strategies. The reason behind this could be that the higher scoring learners obtained rich vocabulary and complex grammatical knowledge and they did not need to depend on any particular strategy. Due to their greater communicative potential, they were aware of their constraints on their target language resources and had the ability to predict the possible problems that may have arisen in their planning process. So a proper strategy could be chosen by the speakers whilst communication was taking place.

The higher scoring learners used the strategy of providing extra information more frequently than the lower scoring learners. By providing further information concerning the target objects, the learners needed to produce more utterances. Therefore, it is reasonable to assume that the higher scoring learners obtained higher English ability that allowed them to explain themselves well by using this strategy.

This finding is in accordance with that of Chen (1990), which showed that the higher English proficiency learners tended to use the strategy of circumlocution, which required the learners to use more language while the lower English proficiency learners preferred to use the strategy of code-switching, which is related to their first language. Therefore, this explained the reason why the lower scoring learners in this study did not favour the use of the strategy of extra information because they had limited English ability.

In addition to discussing the differences of strategy usage between the higher and the lower scoring learners, the researcher also intended to explore how the higher and lower scoring learners used the same strategy at the same task item based on the participants' responses.

By examining speech production data in this study, it was discovered that the lower scoring learners also employed various compensatory strategies during communication. When the lower scoring learners employed the same communication strategies as the high scoring learners, the level of comprehension did not improve and unfortunately resulted in their intended meaning not being explicit.

When considering the issue of the same strategy being adopted by both higher and lower proficiency learners, those low in proficiency could not perform in an equivalent way to the high scoring learners. That is, it is believed that even though the higher and lower scoring learners adopted the same strategy, the higher scoring learners could use it more effectively than the low proficiency learners. The reason for this does not concern the understanding of the use of the communication strategies, but rather the well expressed, grammatically accurate words within their speech. 
When massive grammatical errors and inappropriate language use occurs within conversation, the information cannot be delivered properly and thus causes the communication to break down. This suggests that limited vocabulary, grammatical mistakes or inappropriate language usage could be the reason why the low scoring learners used the same strategy as the higher scoring learners but their communication was not effective.

This researcher also agrees with the interpretation of Chen (1990) in relation to the issue of communication strategies used by lower proficiency learners. As Chen (1990) argues, the low proficiency learners have limitations in their target language which may have affected their surface realisation of the communication strategies, in terms of the grammatical accuracy and informative value. In this case, lower scoring learners would have made grammatical errors and provided insufficient information to their interlocutors. Therefore, Chen (1990) concludes that "the communication strategies employed by high proficiency learners might have been more effective than the same communication strategies employed by low proficiency learners" (p. 176).

\section{IMPLICATIONS FOR LANGUAGE EDUCATION CONTEXT}

Since the Ministry of Education regards the development of language learners' communicative competence as the main goal of reformed English Education, the implementation of the communicative language teaching approach has been expected at all school levels; the English textbooks in Taiwan have also been revised to achieve this goal. However, this research has shown that the learners' cognitive styles concerning the choice of communication strategy and certain other strategies were greatly employed by the learners to overcome their lack of language resources. Furthermore, the strategy usage employed by the higher and lower scoring learners is very similar, but resulted in diversity effects. This shows that grammatical accuracy and informative value were factors while using their communication strategy to express their intended meaning to achieve communicative goals. Some implications for further study will be made in relation to the results of this research in the following sections.

\section{A. Language Teacher}

Language teachers should be aware that their teaching methods should be aimed at developing the learners' strategic competence. This would help to increase the opportunity for the learners to interact with each other by being able to use different strategies to overcome their deficiencies in their English language. That is, there is a necessity to develop their communicative competence through classroom interactions even though most language teachers complain about the restraints on instruction time for class activities. Without interacting with each other, the learners do not have opportunities to effectively apply these communication strategies into their interaction to solve their communication problems. Additionally, the learners will have more opportunities to notice their grammatical errors and expand their vocabulary bank while carrying out their interactions.

\section{B. Language Learners}

There is a need to bring learners' attention to these strategies and help them become more aware of all strategies available to them; in particular, such strategies include those that they may already make use of in the L1 when overcoming their English deficiency, resulting in communication breakdown. Many researchers such as Dörnyei (1995) and Chen (1990) suggest that providing training in how to appropriately use CS in L2, and providing opportunities for practice are essential as it can improve the effective use of the communication strategy.

During the instruction of learners' communication strategy usage, teachers should remind students of what they already do in their L1 and encourage them to do the same in L2, so that instruction can aid strategic transfer by raising awareness of the communication strategy. During practice activities, teachers should not only encourage, but also push learners to use communication strategies. Generally speaking, the purpose of the instructions should focus on helping learners develop and automate more effective strategies to achieve their communicative goals.

\section{Education Department}

The findings of this study could also provide some evidence with regards to a response to the policy of English education reform. Since 2001, the reform of English education attempted to improve the communicative competence of the learners; however, the result does not seem promising. The findings will assist the Ministry of Education in making future policies for developing language learners' communicative competence. Additionally, the findings of this study could produce some benefits to language educators in terms of awareness of the current weaknesses and strengths of English language education, and provide alternative propositions on their decisions regarding selection and design of teaching materials.

\section{Recommendations for Future Studies}

The present study has succeeded in responding to the research questions, which suggests the need for Taiwanese learners of English to develop their communicative language ability in terms of communication strategies. However, there are some perspectives that have not yet been fully explored due to the issue of time constraints on this study. Firstly, it would be advisable to investigate the different ages of the learners who are at different levels of English proficiency in the GEPT. Their results may highlight differences in performance between young and adult participants and learners with different English proficiency in terms of their use of communication strategies. The second 
recommendation relates to the communicative task based activity within the computer mediated environment. This could allow future researchers to explore the communication strategy usage between learners from different locations or even nations. Scope for further research therefore exists in order to explore these issues.

\section{REFERENCES}

[1] Bachman, L. (1990). Fundamental considerations in language testing. New York: Oxford University Press.

[2] Bachman, L., \& Palmer, A. (1996). Language testing in practice: designing and developing useful language tests. Oxford: Oxford University Press.

[3] Bachman, L. (2002). Some reflections on task-based language performance assessment. Language testing, 19 (4), p.453-476.

[4] Bialystok, E. (1990). Communication strategies: A psychological analysis of second language use. Oxford: Blackwell.

[5] Brown, H. D. (2000). Principles of language learning and teaching (4th ed.). White Plains, NY: Longman.

[6] Canale, M., \& Swain, M. (1980). Theoretical based of communicative approaches to second language teaching and testing. Applied linguistics, 1(1), 1-47.

[7] Canale, M. (1983). From communicative competence to language pedagogy. In J. Richards, \& R. Schmidt (eds.), Language and communication, (pp.2-27). London: Longman.

[8] Chalhoub-Deville, M. (2003). Second language interaction: current perspectives and future trends. Language testing, 20(4), 369-383.

[9] Chalhoub-Deville, M. B., \& Deville, C. (2005). A look back at and forward to what language testers measure. In E. Hinkel (ed.), Handbook of research in second language teaching and learning (pp. 815-832). Mahwah, NJ: Lawrence Erlbaum Associates.

[10] Chang, B. L. (2001). The belief of the junior high school teacher towards the communicative teaching approach. Educational Journal, 84, 37-48.

[11] Chang, S. \& Huang Y. K. (2001). Communicative language teaching: senior high school teachers' beliefs and practices. Paper presented at the tenth international symposium on English teaching (pp. 219-217). Taipei: Crane.

[12] Chen, S. Q. (1990). A study of communication strategies in interlanguage production by Chinese EFL learners. Language learning, 40(2), 155-187.

[13] Chomsky, N. (1965). Aspects of the theory of syntax. Cambridge, Mass: MIT Press.

[14] Chomsky, N. (1980). Rules and representations. Oxford: Blackwell.

[15] Council of Europe (1996). Common European framework of reference for languages: learning, teaching, assessment. http://www.coe.int (accessed October 15, 2005).

[16] Dörnyei, Z. (1995). On the teachability of communication strategies. TESOL quarterly, 29 (1), 55-85.

[17] Ellis, R. (1994). The study of second language acquisition. Oxford: Oxford University Press.

[18] Ellis, R. (1999). Theoretic Perspectives on Interaction and Language Learning. In R. Ellis (ed.), Learning a second language through interaction (pp.3-32). Amsterdam: John Benjamins.

[19] Færch, C. \& Kasper, G. (eds.) (1983). Strategies in interlanguage communication. London: Longman.

[20] Fulcher, G. \& Davidson, F. (2007). Language testing and assessment: an advanced resource book. London: Routledge.

[21] GEPT (2006). The Interpretation of Test Scores. http://www.lttc.ntu.edu.tw/96/geptintermediate96.htm (accessed February 15, 2006).

[22] Hymes, D. (1967). Models of the interaction of language and social setting. In J. Macnamara (ed.), Problem of bilingualism. Journal of social issue, 23, 8-28.

[23] Hymes, D. (1972). On communicative competence. In J.B. Pride and J. Holmes (eds.), Sociolinguistics. England: Penguin Books.

[24] Jacoby, S. \& Ochs, E. (1995). Co-construction: an introduction. Research on language and social interaction, $28,171-183$.

[25] Kellerman, E., Bongaerts, T., \& Poulisse, N. (1987). Strategy and system in L2 referential communication. In R. Ellis (ed.), Second language acquisition in context (pp.100-112). N.J.: Prentice Hall International.

[26] Liao, P. S. (2004). English as a global language and its effects on Taiwan's English education. Studies in English language and linguistics, 29 (1), 107-121.

[27] Liao, P. S. (2006). English profession is better than survival skills of college students (in Chinese). http://ejee.ncu.edu.tw/articles.asp?period=28\&flag=28 (accessed October 5, 2006).

[28] Littlemore, J. (2003). The communicative effectiveness of different types of communication strategy. System, 31, $331-347$.

[29] Littlemore, J. \& Low, G. (2006). Metaphoric competence, second language learning, and communicative language ability. Applied linguistics, 27 (2), 268-294.

[30] McNamara, T. (1996). Measuring second language performance. London and New York: Longman.

[31] Poulisse, N. (1990). The use of compensatory strategies by Dutch learners of English. Dordrecht: Foris.

[32] Poulisse, N. (1993). A theoretical account of lexical communication strategies. In R. Schreuder and B. Weltens (eds.), The bilingual lexicon (pp.157-89). Amsterdam: John Bejamins.

[33] Savignon, S. J. (1983). Communication competence: theory and classroom practice. Reading MA: Addison-Wesley.

[34] Schachter, J. (1990). Communicative competence revisited. In B. Harley, P. Allen, J. Cummins, \& M. Swain (eds.), The development of second language proficiency (pp. 39-49). Cambridge: Cambridge University Press.

[35] Smith, B (2003). The use of communication strategies in computer-mediated communication. System, 31, 29-53.

[36] Swain, M. (2001). Examining dialogue: another approach to content specification and to validating inferences drawn from test scores. Language testing, 18, 275-302.

[37] Tarone, E. (1977). Conscious communication strategies in interlanguage. In H. Brown, C. Yorio \& R. Crymes (eds), On TESOL '77: teaching and learning English as a second language : Trends in Research and Practice (pp.194-203). Washington, DC: TESOL.

[38] Widdowson, H. G. (1989). Knowledge of language and ability for use. Applied linguistics, 10 (2), 128-37. 
[39] Young, R. F. (2000, March). Interactional competence: challenges for validity. Paper presented at the Language Testing Research Colloquium. Vancouver, Canada.

Ying-Chuan Wang holds a PhD in Applied Linguistics and TESOL from the University of Leicester in U.K. She is currently an Assistant Professor in Macau University of Science and Technology. Her major research interests include the theories and practice of interlanguage communication, communicative competence, communication in hotel and tourism industry, and computer-assisted language learning. 